\title{
A CONSTITUCIONALIDADE DA APLICAÇÃO DA TEORIA DA CEGUEIRA DELIBERADA NAS CONDENAÇÕES DOS CASOS DA OPERAÇÃO LAVA JATO
}

\section{JAQUELINE MARIA RYNDACK}

Advogada. Mestranda e bacharela em Direito - Centro Universitário Curitiba UNICURITIBA. Pós Graduanda pela Fundação Escola do Ministério Público do Estado do Paraná - FEMPAR. E-mail: ryndack.jaqueline@hotmail.com

\section{RESUMO}

A presente pesquisa tem por objetivo geral perquirir sobre a constitucionalidade da aplicação da Teoria da Cegueira Deliberada nas condenações dos casos da chamada Operação Lava Jato.

O presente trabalho caracteriza-se pela revisão bibliográfica, como pesquisa em dissertação, artigos e jurisprudência nacional, a fim de realizar um levantamento da aplicabilidade da Teoria da Cegueira Deliberada e a sua constitucionalidade.

A Teoria da Cegueira Deliberada, também conhecida como a Teoria das Instruções de Avestruz ou ainda como a Doutrina da Evitação de Consciência, de acordo com Marco Antonio de Barros e Thiago Minetti Apostólico Silva,

[...] constitui uma tese jurídica por meio da qual se busca atribuir responsabilidade penal àquele que, muito embora esteja diante de uma conduta possivelmente ilícita, se autocoloca em situação de ignorância, evitando todo e qualquer mecanismo apto a conceder-Ihe maior grau de certeza quanto à potencial antijuridicidade. ${ }^{1}$

\footnotetext{
${ }^{1}$ BARROS, Marco Antonio de; SILVA, Thiago Minetti Apostólico. Lavagem de ativos: dolo direto e a inaplicabilidade da teoria da cegueira deliberada. Curitiba: Revista dos Tribunais. Ano 104, v. 957, 2015, p. 231.
} 
Personalidade Acadêmica Homenageada:

Carlos Aurélio Mota de Souza (Universidade Ibirapuera - UNIB)

No mesmo sentido, contudo aos olhos dos autores Evandro Augusto Dell Santos e Diane Fernandes Fornaciari,

\begin{abstract}
A Teoria da Cegueira Deliberada (willful blindness), também conhecida como Teoria das Instruções de Avestruz (ostrich intructions), ou, ainda, como Doutrina da Evitação da Consciência (conscious avoindance doctrine), trata-se de construção jurisprudencial de origem inglesa e norte-americana, assemelhada à formulação do dolo eventual, consolidada, a princípio, em sede de crimes de lavagem de capitais. Com efeito, em face destes crimes, com esteio na Ostrich Instructions Doctrine, passou-se a considerar merecedor de condenação criminal, aquele que tem o dever de evitar o resultado e, embora possua mecanismos para averiguar a natureza de determinados bens, opta pela ignorância deliberada, comportando-se como avestruz, que enterra a cabeça na terra para não ver a luz do sol. ${ }^{2}$
\end{abstract}

Desse modo, pode-se entender que a Teoria da Cegueira Deliberada ocorre quando o agente, deliberadamente, deixa de tomar e aprofundar o conhecimento de circunstâncias objetivas quando há situações suspeitas e que, por sua posição, existe a obrigatoriedade do dever de vigilância.

Tratando do assunto sob a sua aplicação nas condenações dos crimes tratados no âmbito da Operação Lava Jato, temos as condenações do empresário Adir Assad, do ex-marqueteiro João Santana e de sua esposa Mônica Moura, entre outros exemplos. Conforme observação de Renato de Mello Jorge Silveira, tal princípio vem sendo aplicado na modalidade de dolo eventual:

De todo modo, e mesmo que não se possa dizer de uma real tendência na jurisprudência nacional, é de se ver que, em especial junto à 13. ${ }^{\mathrm{a}}$ Vara Criminal Federal do Paraná, durante o julgamento dos casos derivados da Operação Lava Jato, percebe--se, com ampla repercussão nacional, a utilização do paralelismo da cegueira/ignorância deliberada em sede nacional. E é esse o ponto aqui de debate, vale dizer, da correção de tal utilização. Assim, entre tantas, verificam-se as colocações na Sentença da AP 5026212-82.2014.4.04.7000/PR, as quais são repetidas, a seu modo em diversas outras decisões relativas à mesma Operação. Diz a Sentença, em

2 SANTOS, Evandro Augusto Dell; FORNACIARI, Diane Fernandes. Da aplicabilidade da teoria da cegueira deliberada nas ações de improbidade administrativa. Revista Jurídica do Ministério Público do Estado do Paraná. Ano 3, n. 5. Disponível em: <http://femparpr.org.br/site/wpcontent/uploads/2016/12/Revista-MPPR-5\%C2\%AA-Edi\%C3\%A7\%C3\%A3o.pdf>. Acesso em: 22/10/2018. 
Personalidade Acadêmica Homenageada:

Carlos Aurélio Mota de Souza (Universidade Ibirapuera - UNIB)

análise pontual à permissividade da utilização do instituto do dolo eventual em relação à lavagem de dinheiro ${ }^{3}$

Acerca da discussão da aplicação do dolo eventual, na tese de Doutorado de Guilherme Brenner Lucchesi, ele apresenta a incompatibilidade da relação entre dolo eventual e o Princípio da Cegueira Deliberada. Segundo ele,

\begin{abstract}
Para além das impropriedades conceituais e os equívocos no emprego da metodologia do direito comparado, há um falha na proposição de equivalência entre cegueira deliberada e dolo eventual. Se cegueira deliberada equivale a dolo eventual, não é necessário se construir uma teoria sobre cegueira deliberada. Bastaria aplicar o dolo eventual. Se o conceito de dolo eventual é insuficiente, havendo uma lacuna de punibilidade, não basta dizer que cegueira deliberada é dolo eventual. Seria preciso dizer mais, propondo critérios adicionais para a cegueira deliberada, que a distinguiriam do dolo eventual. ${ }^{4}$
\end{abstract}

Retornando sobre a aplicação do citado princípio como fundo para a condenação de crimes, o juiz Sérgio Moro, responsável pela 13aㅡ Vara Federal em

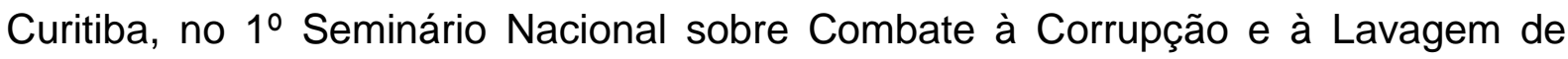
Dinheiro, afirmou não verificar obstáculos jurídicos ou morais para atribuir aos doleiros o papel de réus, por mais que os mesmos aleguem ignorância a fim de evitarem a responsabilização criminal. ${ }^{5}$

No tocante a constitucionalidade, percebe-se que a aplicação do Princípio da Cegueira deliberada não viola a Carta Magna, vez que permite ao acusado o contraditório e a ampla defesa (art. 5ำ, LV da Constituição Federal), além de conservar o princípio da legalidade (art. 5º, XXXIX da Constituição Federal).

3 SILVEIRA, Renato de Mello Jorge. A aplicação da teoria da cegueira deliberada nos julgamentos da Operação Lava Jato. Revista Brasileira de Ciências Criminais. Disponível em: $<$ http://www.mpsp.mp.br/portal/page/portal/documentacao_e_divulgacao/doc_biblioteca/bibli_servicos _produtos/bibli_boletim/bibli_bol_2006/122.10.PDF>. Acesso em: 22/10/2018.

${ }_{4}^{4}$ LUCCHESI, Guilherme Brenner. A punição da culpa a título de dolo: o problema da chamada "cegueira deliberada". 368f. Tese (Doutorado) - Doutorado em Direito do Estado, Universidade Federal do Paraná, Curitiba, 2017, p. 224 - 225.

5 SENADO. O juiz Sérgio Moro, responsável pelas ações da Lava-Jato, exortou ontem o Judiciário a discutir o papel dos doleiros em crimes de lavagem de dinheiro. Disponível em: $<$ https://www2.senado.leg.br/bdsf/bitstream/handle/id/504607/noticia.html?sequence=1 $>$. Acesso em: 22/10/2018. 
Personalidade Acadêmica Homenageada:

Carlos Aurélio Mota de Souza (Universidade Ibirapuera - UNIB)

PALAVRAS-CHAVE: Cegueira Deliberada; Teoria das Instruções de Avestruz; Constitucionalidade; Operação Lava Jato.

\section{REFERÊNCIAS}

BARROS, Marco Antonio de; SILVA, Thiago Minetti Apostólico. Lavagem de ativos: dolo direto e a inaplicabilidade da teoria da cegueira deliberada. Curitiba: Revista dos Tribunais. Ano 104, v. 957, 2015, p. 203 - 256.

LUCCHESI, Guilherme Brenner. A punição da culpa a título de dolo: o problema da chamada "cegueira deliberada". 368f. Tese (Doutorado) - Doutorado em Direito do Estado, Universidade Federal do Paraná, Curitiba, 2017.

SANTOS, Evandro Augusto Dell; FORNACIARI, Diane Fernandes. Da aplicabilidade da teoria da cegueira deliberada nas ações de improbidade administrativa. Revista Jurídica do Ministério Público do Estado do Paraná. Ano 3, n. 5. Disponível em: <http://femparpr.org.br/site/wp-content/uploads/2016/12/Revista-MPPR-5\%C2\%AAEdi\%C3\%A7\%C3\%A3o.pdf>>. Acesso em: 22/10/2018.

SENADO. O juiz Sérgio Moro, responsável pelas ações da Lava-Jato, exortou ontem o Judiciário a discutir o papel dos doleiros em crimes de lavagem de dinheiro. $<$ https://www2.senado.leg.br/bdsf/bitstream/handle/id/504607/noticia.html?sequence $=1>$. Acesso em: 22/10/2018.

SILVEIRA, Renato de Mello Jorge. A aplicação da teoria da cegueira deliberada nos julgamentos da Operação Lava Jato. Revista Brasileira de Ciências Criminais. Disponível em: <http://www.mpsp.mp.br/portal/page/portal/documentacao_e_divulgacao/doc_bibliote ca/bibli_servicos_produtos/bibli_boletim/bibli_bol_2006/122.10.PDF $>$. Acesso em: 22/10/2018. 